\title{
Mulheres e política nas notícias: Estereótipos de gênero e competência política
}

Women and Politics in the News: Gender Stereotypes and Political Competence

Femmes et politiques dans la presse : stéréotypes de genre et compétence

politique

\section{Flávia Biroli}

\section{CpenEdition}

\section{Journals}

\section{Edição electrónica}

URL: http://journals.openedition.org/rccs/1765

DOI: $10.4000 /$ rccs. 1765

ISSN: 2182-7435

Editora

Centro de Estudos Sociais da Universidade de Coimbra

Edição impressa

Data de publição: 1 setembro 2010

Paginação: 45-69

ISSN: 0254-1106

\section{Refêrencia eletrónica}

Flávia Biroli, «Mulheres e política nas notícias: Estereótipos de gênero e competência política »,

Revista Crítica de Ciências Sociais [Online], 90 | 2010, posto online no dia 15 outubro 2012, consultado o 10 dezembro 2020. URL : http://journals.openedition.org/rccs/1765 ; DOI : https://doi.org/10.4000/ rccs. 1765

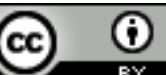




\title{
FLÁVIA BIROLI
}

\section{Mulheres e política nas notícias: Estereótipos de gênero e competência política'}

\begin{abstract}
O artigo analisa representações de gênero presentes nas notícias das principais revistas semanais brasileiras. Constata que a presença reduzida de mulheres é acompanhada da existência de estereótipos que remetem a certas concepções do papel da mulher nas sociedades e de sua competência para atuar na vida pública. A relação da mulher com a vida privada é a espinha dorsal desses estereótipos. Seu complemento é o destaque à aparência e o reforço à beleza como um modo de distinção feminina. $\mathrm{O}$ artigo apresenta uma análise qualitativa da presença das três mulheres que tiveram maior visibilidade nas notícias no período analisado, os anos de 2006 e 2007: Heloisa Helena, Marta Suplicy e Dilma Rousseff. Essa análise permite discutir representações da feminilidade e da masculinidade, do privado e do público, que atribuem sentidos à presença diferenciada de homens e mulheres na política e na mídia.
\end{abstract}

Palavras-chave: estereótipos; mídia; política; representação de gênero.

\section{Introdução}

Este artigo discute a convivência entre a presença reduzida das mulheres nas secções de notícias das principais revistas semanais brasileiras e a existência de estereótipos de gênero que remetem a compreensões convencionais do papel da mulher nas sociedades e de sua competência para atuar na vida pública. A partir de pesquisa que realizou um amplo mapeamento da presença feminina nos noticiários políticos dos principais telejornais noturnos e revistas semanais brasileiras, analisa a presença das três mulheres citadas com maior freqüência nas revistas semanais Veja, Época e Carta Capital, nos anos de 2006 e 2007: a ex-senadora e então candidata à presidência da República Heloisa Helena, a ex-prefeita da cidade de São Paulo

\footnotetext{
${ }^{1}$ As discussões contidas neste artigo resultaram das pesquisas "Determinantes de gênero, visibilidade midiática e carreira política no Brasil" e "Gênero e política na mídia brasileira", financiadas pelo CNPq (editais 45/2005 e 57/2008, respectivamente, e bolsas PQ e IC). Para outros desdobramentos dessas pesquisas, conferir Miguel e Biroli (2011).
} 
e ex-ministra Marta Suplicy, e a ministra da Casa Civil Dilma Rousseff, que seria eleita presidente da República nas eleições de 2010, em que foi candidata pelo PT à sucessão de Luiz Inácio Lula da Silva.

A sub-representação das mulheres na política está relacionada, ao mesmo tempo, a dois conjuntos de problemas. Um deles, mais amplo, é relativo ao funcionamento das democracias liberais, nas quais a igualdade formal convive com formas sistemáticas de exclusão de alguns grupos sociais. O outro remete, de maneira mais específica, à manutenção das mulheres em posições subalternas em sociedades nas quais o direito à participação política foi universalizado e não existem restrições formais à sua inclusão nas mais diversas esferas, entre elas a política. A mídia pode ser pensada como esfera que participa ativamente da reprodução ou da transformação de práticas, valores e instituições que configuram as formas atuais da representação e da participação política nas democracias e legitimam as formas assumidas pelas relações de gênero.

O problema central que determina a abordagem proposta é o de que à sub-representação das mulheres nos espaços formais de poder político soma-se a sua sub-representação na mídia, especialmente no noticiário político, foco da pesquisa. Essa presença reduzida é, por sua vez, marcada por estereótipos de gênero e vinculada a posições de menor prestígio, reforçando a posição marginal das mulheres na política. Entende-se que a discussão sobre a sub-representação de mulheres nos espaços de poder deve levar em conta a forma como a mídia representa a política e, nela, as relações de gênero. Deve, portanto, levar em conta aspectos relevantes do funcionamento da mídia, que têm impacto sobre os significados assumidos pela atuação das mulheres nas várias esferas sociais, entre elas a política.

Os dados apresentados demonstram que as mulheres são, predominantemente, invisíveis nos noticiários políticos. Além disso, a visibilidade feminina na mídia noticiosa é concentrada em algumas poucas mulheres e produzida por filtros que reafirmam, de múltiplas maneiras, as separações tradicionais que associam as mulheres à esfera doméstica e íntima, à emotividade e ao corpo. O desinteresse pela política, a falta de habilidade para o exercício de cargos públicos e o não-pertencimento à esfera política em sentido estrito são, assim, conectados em um conjunto de discursos que atendem a uma regularidade sem que se apresentem de forma homogênea. A oposição entre, de um lado, feminino e espaço privado, e, de outro, masculino e espaço público, discutida em estudos como os das cientistas políticas Carole Pateman (1993) e Susan Okin (1998, 1989), está na base desses estereótipos, confirmando divisões e hierarquias que colaboram para a marginalização das mulheres da e na esfera política. 
É importante deixar claro que a perspectiva aqui assumida é a de que não se trata de uma relação causal simples entre o campo político e o campo da mídia - em que as formas assumidas pela representação feminina na mídia seriam simplesmente um "espelho" da sub-representação na política ou, em sentido inverso, em que a sub-representação na política seria um efeito direto da pouca visibilidade das mulheres na mídia ou dos filtros que as mantêm em posição de pouca relevância nas secções de notícias.

Os estereótipos de gênero presentes na mídia devem ser entendidos como produtos de uma dinâmica social complexa, que envolve a determinação de papéis diferenciados, e hierarquicamente distintos, para homens e mulheres. Por outro lado, esses estereótipos são reproduzidos de acordo com as rotinas produtivas dos meios de comunicação de massa e as perspectivas sociais dos jornalistas, definindo quais os temas e vozes que constituem as notícias (Miguel e Biroli, 2010).

A seleção dos temas e personagens presentes na cobertura jornalística atende a critérios específicos de relevância, que fazem parte da rotina que organiza o trabalho jornalístico. O entendimento de que essa seleção não é natural ou dada, mas fruto de modos de compreender a realidade que são reveladores do funcionamento do jornalismo e de suas interações com outras esferas sociais, é um dos pressupostos básicos da ampla maioria dos estudos sobre as relações entre os meios de comunicação e a política. Conceitos centrais a esse campo de estudos, como os de agenda setting e enquadramento (McCombs e Shaw, 2000; Goffman, 1986), remetem a esses pressupostos. Soma-se a isso o fato de que o acesso a muitos aspectos da realidade e o próprio entendimento do que é atual derivam do contato com as informações difundidas pela mídia. Os meios de comunicação têm um papel ativo na definição do que é socialmente relevante - em grande parte porque a própria centralidade da mídia nas sociedades contemporâneas amplia a sobreposição entre relevância social e visibilidade produzida pelo advento da política de massas, especialmente a partir das primeiras décadas do século XX.

Existe uma relação direta entre a definição dos temas presentes no noticiário, as narrativas em que esses temas se inserem e a seleção de quem tem voz nos debates que ganham tempo e espaço nos meios de comunicação. Ao argumentar pelo entendimento do jornalismo como uma cultura, Michael Schudson (1995: 14) lembra que mais do que responder às questões "quem”, "o quê", "quando", “onde" e "porquê", o jornalismo seleciona quais categorias de pessoas contam como o "quem" da notícia, que tipos de coisas são fatos ou o "o quê" da notícia. O mesmo se passa na definição do espaço e tempo em que as histórias se dão e na definição das causas e motivações para as ações que se tornaram notícia. 
Na pesquisa discutida neste artigo, o "quem" das notícias é particularmente relevante. Ao ativar determinadas compreensões da realidade, o jornalismo confirma e ao mesmo tempo promove determinados atores sociais ao lugar de enunciadores privilegiados, isto é, de indivíduos que têm competência e recursos para dizer algo que merece a atenção do público. Estudos sobre o noticiário de telejornais e revistas impressas brasileiras apontam para o fato de que quem tem voz no noticiário político são os ocupantes de cargos e posições de destaque no campo político em sentido estrito (Gomes, 2008; Miguel e Biroli, 2008). Assim, mais do que colocar-se a favor de uma ou outra posição no espectro político (candidatos, partidos, governos), o jornalismo confirmaria as hierarquias correntes ao atribuir mais voz a quem já a detém, pela posição que ocupa em sua esfera de atuação, e menos voz ou o silêncio justamente a quem está em posições marginais nos campos em que trava suas próprias disputas. Com isso, naturaliza, grosso modo, a configuração atual da política e a marginalidade que implica para indivíduos e grupos sociais com perfis que, por várias razões, não coincidem com os daqueles que ocupam as posições mais centrais - na política e na mídia.

\section{Público, privado e estereótipos de gênero}

A naturalização da exclusão das mulheres da esfera pública e, particularmente, dos cargos políticos eletivos, vem sendo um fator de legitimação da política como "negócio de homens". As mulheres não se interessariam pelos debates políticos e, menos ainda, por participar da política institucional porque estariam, naturalmente, voltadas para o que lhes seria mais caro: a vida privada, a esfera doméstica, a maternidade. A crítica feminista e a atuação política a ela correspondente confrontam-se com práticas e valores patriarcais que se atualizam, tendo como um de seus eixos a afirmação do desinteresse feminino pela política, o silêncio sobre a atuação pública das mulheres e, no limite, a reprodução de estereótipos de gênero.

As definições assumidas pela oposição público-privado na modernidade têm o gênero como um elemento central. Para Pateman, em estudo que se tornou referência central para esse debate,

A esfera privada, feminina (natural) e a esfera pública, masculina (civil) são contrárias, mas uma adquire significado a partir da outra, e o sentido de liberdade civil da vida pública é ressaltado quando ele é contraposto à sujeição natural que caracteriza o domínio privado. (Pateman, 1993: 28)

A partir da análise das teorias contratualistas, a autora ressalta que é o direito patriarcal (moderno) dos homens que constitui as noções de 
indivíduo e universalidade que estruturam a compreensão liberal da esfera pública. A subordinação das mulheres aos homens, tanto na vida privada quanto na pública, seria o elo que estabelece as relações entre as duas esferas, fazendo com que, na modernidade, a subordinação feminina seja inseparável da liberdade e autonomia dos "cidadãos".

O feminismo coloca um desafio significativo ao pressuposto que vem há muito tempo sustentando boa parte das teorias políticas de que a esfera da família e da vida pessoal é tão separada e distinta do resto da vida social que essas teorias poderiam legitimamente ignorá-la (Okin, 1998; Biroli, 2010). Ao mesmo tempo, vários estudos permitem questionar a vinculação entre a participação da mulher na vida pública e uma suposta sensibilidade moral especial, desenvolvida na esfera doméstica, que seria a contribuição dessas mulheres à política (Badinter, 1980 e 2005; Okin, 1989; MacKinnon, 1989).

A posição assumida nesta pesquisa está de acordo com a visão de Iris M. Young $(1990,2000)$ de que as diferenças de gênero são estruturais e, como tal, demarcam possibilidades específicas de atuação e excluem outras. Trata-se, assim, de operar não com uma condição feminina baseada em atributos morais ou em interesses unificados por essa condição, mas com um conjunto de perspectivas que constituem e diferenciam o posicionamento das mulheres em relações de poder marcadas centralmente pelo gênero. Para Young, cada perspectiva social é particular e parcial em relação ao campo social como um todo. Seu apagamento significaria, assim, o apagamento das trajetórias no que elas têm de politicamente significativo, na medida em que permitem que sejam vislumbrados aspectos da realidade social que não se tornam visíveis, da mesma maneira, pela expressão das trajetórias e experiências de outros grupos.

Explicitada essa posição, vale destacar que esse debate remete a tensões teóricas e políticas com as quais procuramos lidar.

Podemos observar, com Pateman (1990: 60), que tanto a exclusão das mulheres da vida política quanto sua inclusão estão historicamente associadas a suas diferenças em relação aos homens - "as mulheres vêm sendo excluídas e incluídas como mulheres”. A contraposição à universalidade que constituiria as categorias liberais de indivíduo e cidadão, ocultando as relações de gênero que demarcam espaços e possibilidades, implicaria, para a autora, na elaboração de concepções "sexualmente diferenciadas" de cidadania, reconhecendo as mulheres como mulheres (Pateman, 1990; e Pateman, 1986 apud Mouffe, 2005: 80).

A noção de perspectiva, tal como trabalhada por Young e mencionada mais acima, nos permite levar em conta essa ambigüidade, incorporando, 
porém, as críticas feitas por Mouffe (2005) à própria Pateman. Para Mouffe, a proposta de uma cidadania (ou atuação política, no foco desta pesquisa) que reconheça a feminilidade se ancora na identificação das mulheres com a maternidade, levando à afirmação de alguma essência que caracterizaria as mulheres como mulheres. $\mathrm{O}$ argumento de Pateman, radicalizado por autoras relacionadas ao pensamento maternal, como Sarah Ruddick, Jean Bethke Elshtain e Carol Gilligan, pode se contrapor de maneira eficaz à universalização e abstração que definem as categorias liberais de cidadania e individualidade, mas não é capaz de desconstruir a oposição homem/mulher e os sentidos a ela associados.

É preciso levar em consideração que o recurso aos papéis sociais tradicionalmente reservados às mulheres pode ser, ao mesmo tempo, um obstáculo a uma atuação política mais destacada $e$ uma estratégia de diferenciação e ação política por parte das mulheres. Ao discutirmos a presença de mulheres nas secções de notícias políticas, é preciso ter em mente: (1) que se trata de pensar a presença de mulheres como uma potencialidade de ruptura com a oposição masculinidade/esfera pública versus feminilidade/esfera privada, uma vez que essa presença pode significar uma ruptura com a categoria supostamente universal e abstrata de indivíduo que vem embasando a política liberal e suas formas reiteradas de exclusão, mas (2) que a mera presença, quantitativamente falando, não indica por si só uma potencialidade de reconfiguração dessa oposição e das relações de gênero que ela embasa, daí a importância de se trabalhar a relação entre gênero e estereótipos. É neste último sentido que se considera que a presença (assimétrica) de homens e mulheres nas secções de notícias, perpassada por estereótipos de gênero, pode significar a confirmação e naturalização, pela mídia, de papéis hierarquicamente diferenciados para homens e mulheres.

A pesquisa realizada indica que a visibilidade do privado, do íntimo e do que concerne o corpo e a aparência física atende a uma clivagem de gênero. Isso significa que a privacidade é demarcada por fronteiras menos ou mais tênues e tem sentidos diferenciados se quem foi alçado à condição de personagem na cobertura jornalística é homem ou mulher. Dito de outro modo, a relação entre os temas presentes na cobertura jornalística e as esferas pública e privada oscila e essa oscilação está fortemente relacionada à presença e centralidade de mulheres nos noticiários políticos.

Um aspecto importante da relação entre agenda, enquadramento e voz nos meios de comunicação é, assim, a incorporação e reprodução da dualidade entre a esfera pública e a esfera privada. O limite entre o que (e quem) tem e o que (e quem) não tem relevância na mídia e, especialmente, no 
noticiário político é fruto, entre outras variáveis, da presunção de que a oposição entre público e privado atende a padrões que não precisam ser questionados e corresponde a hierarquias que não são, do mesmo modo, objeto de contestação. E se as fronteiras se deslocam quando as poucas personagens femininas que ganham centralidade no noticiário estão em evidência, esse deslocamento não rompe com a hierarquia entre as esferas. Pelo contrário, a associação entre mulher e espaço privado produz, duplamente, a pouca visibilidade das mulheres no noticiário e sua presença marcada por estereótipos de gênero. Aqui, como em outros aspectos das representações de atores e esferas da sociedade, as práticas sociais e as convenções literárias do jornalismo "refletem, incorporam e reforçam estruturas e valores de um mundo social particular de maneiras que testemunham tanto a estrutura e os valores do jornalismo quanto do 'mundo' que o jornalismo presume cobrir" (Schudson, 1995: 15).

\section{Gênero, mídia e política}

Em compasso com as mudanças mais amplas que ocorreram nas sociedades que se organizam por instituições e valores liberais, pode-se trabalhar com a hipótese de que existe cada vez menos discriminação aberta de sexo, gênero e raça nos meios de comunicação. A expressão e pressão de movimentos sociais como o movimento negro, o movimento LGBTT e o movimento feminista podem ser consideradas parcialmente responsáveis por essa mudança, agindo por meio de ONGs ou mesmo observatórios de mídia. Mas o próprio peso e amplitude desses movimentos são possíveis porque existem graus mínimos de garantia à pluralidade e porque há, em alguma medida, uma aceitação de que as diferenças (ou algumas delas) devem ser respeitadas.

A diminuição ou ausência de discriminação aberta (como o veto explícito ao acesso dos indivíduos a espaços e posições específicas) não garante, no entanto, que o cotidiano das sociedades liberais seja livre de formas de opressão que restringem as possibilidades de autodeterminação dos indivíduos. Ao contrário, a posição de subalternidade de alguns grupos sociais convive com a universalização dos direitos e, em alguns casos, com formas de valorização de diferenças. Nos meios de comunicação, isso significa dizer que a ausência de normas ou posições abertamente sexistas, por exemplo, não garante visibilidade simétrica a homens e mulheres. Há uma convivência entre o ideal de imparcialidade e objetividade que legitima o trabalho jornalístico e faz parte do ethos dos jornalistas (Tuchman, 1992) e o tratamento diferenciado que os grupos sociais recebem no noticiário, com impacto sobre suas possibilidades de expressão e autodeterminação (Miguel e Biroli, 2010). 
Os meios de comunicação de massa são aqui considerados aparatos técnicos de mediação simbólica que transformaram a natureza das interações sociais e as percepções que indivíduos e grupos têm de si mesmos e dos outros (Thompson, 1995). Isso significa que os juízos e valores que organizam a experiência são confirmados, (re)produzidos e transformados pela mídia. Indivíduos e temas ganham relevância e são julgados, em maior ou menor medida, por sua presença na agenda dos meios de comunicação de massa e por sua inserção em narrativas que atribuem sentido à experiência social.

A dinâmica atual de produção do noticiário é marcada pelas formas institucionalizadas do campo da mídia e pelos interesses e perspectivas sociais dos jornalistas. O resultado é um noticiário repetitivo, em que os diferentes veículos e produtos jornalísticos incorporam grades de relevância e procedimentos comuns na escolha das fontes e no acesso a informações, difundindo representações do campo político e dos agentes políticos que confirmam as formas atuais de distribuição de capital e reconhecimento naquele campo.

Nesse contexto - de produção de silêncios e de uma visibilidade que toma forma a partir de filtros comuns -, as representações sobre a feminilidade presentes na mídia podem reforçar uma série de estereótipos ligados aos papéis de gênero. Para Norris (1997: 8), os enquadramentos predominantes na representação da atuação política das mulheres, nos quais se localizam, com variações, os estereótipos de gênero, são um produto das interações entre a mídia, as fontes no jornalismo e o público. A partir do trabalho de Gaye Tuchman, já mencionado, Norris destaca que é preciso observar o modo como rotineiramente a mídia lida com as histórias que constituem as notícias, considerando a institucionalização dos enquadramentos pelas empresas, o treinamento e a cultura profissional, as práticas e valores ligados à produção da notícia.

Uma questão a ser considerada, nesse sentido, é se as representações sobre o masculino e o feminino nas secções de notícias estão marcadas por associações tradicionais entre a feminilidade e os papéis e expectativas relacionados à esfera privada e, no limite, à maternidade. É preciso considerar em que medida, de fato, esses estereótipos estão presentes no discurso jornalístico, como eixos centrais aos enquadramentos e padrões discursivos em que se insere a atuação política feminina quando esta é visivel. Estudos sobre a presença de lideranças femininas nos noticiários e sobre campanhas políticas de mulheres apontam para o fato de que as próprias candidatas podem lançar mão desses estereótipos para obter sucesso nas urnas e galgar posições, na mídia e na política (Iyengar et al., 1997). Outros estudos 
concluem que a invisibilidade é o problema mais central quando se analisa a mídia noticiosa, mas que uma vez visíveis na mídia, não são predominantes representações estereotipadas e enquadramentos negativos focados no gênero (Carroll e Shreiber, 1997).

Entende-se, como já foi dito, que a "mera presença" de vozes femininas nos noticiários não garante deslocamentos em relação a práticas políticas e a discursos convencionais sobre a política e sobre as relações de gênero. Sua exclusão ou sua presença reduzida, marcada por estereótipos, indica, no entanto, que os filtros que definem quem estará presente nos noticiários, e como estará presente, incidem diferentemente sobre homens e mulheres.

Algumas questões precisam ser consideradas. Não é possível estabelecer uma correspondência entre a presença de mulheres e uma "voz feminina". Tal correspondência levaria a uma essencialização do feminino e a uma desconsideração da complexidade do conceito de perspectiva, apresentado antes neste artigo (Young, 1990 e 2000). Em segundo lugar, não existe uma correlação necessária entre presença feminina e "voz feminista", aqui entendida no sentido da materialização, nos noticiários, de discursos críticos às relações hierárquicas entre os gêneros e à oposição entre masculino/público e feminino/privado. Isso significa, entre outras coisas, uma clareza em relação ao fato de que um aumento da presença de mulheres em esferas de poder e de visibilidade não implica, necessariamente, a promoção de perspectivas críticas às relações convencionais de gênero e, mesmo, ao problema específico da sub-representação das mulheres em espaços de poder.

A análise de estereótipos de gênero nos noticiários pode servir para discutir a complexidade da atuação dos meios de comunicação e do jornalismo, em especial, em meio a arranjos sociais estruturados e de grande permanência. Em primeiro lugar, a mídia não produz os estereótipos, mas atua no sentido de reforçá-los ou confrontá-los. Pode, mesmo, mobilizar esses estereótipos de maneira localizada, enquanto os questiona em padrões discursivos que adquirem estabilidade relativa em um dado momento ou, ao contrário, pode apresentar posições críticas em circunstâncias específicas enquanto mantém, em ampla medida, uma relação estreita com as convenções e papéis socialmente estruturados. Em segundo lugar, os estereótipos não são associados às mulheres sempre a partir de condições externas, isto é, podem fazer parte de suas próprias estratégias para alcançar a visibilidade. Mas, principalmente, podem constituir suas identidades de maneiras complexas.

No debate feminista, há, em várias vertentes, a preocupação com o fato de que as mulheres tendem a enxergar seus próprios corpos e, portanto, 
constituir suas identidades a partir de uma perspectiva masculina. Para Catherine MacKinnon (1989), por exemplo, isso significa que as mulheres constroem a visão que têm de si mesmas a partir dos recursos que sua condição de subordinação lhes oferece, isto é, a partir da internalização dos valores que confirmam e reproduzem sua condição de dominadas. Em outras vertentes do pensamento feminista, destaca-se uma outra questão, a de que a vivência do corpo, da sexualidade e de outros aspectos da experiência das mulheres não se esgota nas representações masculinas sobre a feminilidade. Há mais nessas experiências do que a oposição entre dominador e dominado permite apreender. Seria preciso, assim, levar em conta "mecanismos estruturais mais impessoais que são vividos em meio a formas culturais mais fluidas" (Fraser, 1997: 235). Por um lado, a subordinação continua a ser reproduzida mesmo quando as mulheres não estão mais sob o comando direto de homens específicos, por outro, existem novas formas de resistência política e contestação cultural.

Nos meios de comunicação, coloca-se o problema das fronteiras entre a imposição de uma lógica específica para a produção da visibilidade e da relevância pública - uma lógica midiática - e a incorporação e utilização dessa mesma lógica pelos diferentes atores sociais. O domínio dessa lógica pode denotar, ao mesmo tempo, a incorporação de suas premissas e a possibilidade potencialmente ampliada de agir sobre essa mesma lógica de modo a beneficiar-se dela, pressioná-la e mesmo, no limite, modificá-la. As relações entre agenda, voz e vida privada apresentam essa variação - ou tensão - entre a imposição de uma lógica, que nesse caso está relacionada à confirmação de estereótipos de gênero, e o recurso pelas mulheres a essa mesma lógica (e aos estereótipos que envolve) para garantir visibilidade.

A visibilidade restrita é um dos problemas para a afirmação política das mulheres (individualmente, para suas carreiras, e de modo amplo, para a visibilização de suas experiências e pontos de vista). E os estereótipos completam esse quadro. A visibilidade possível, antes mesmo de ser negativa ou positiva para a trajetória individual das mulheres que ganham espaço na cobertura jornalística, está relacionada à divisão dos papéis sexuais e à dualidade entre público e privado. A visibilidade maior do corpo e as "demandas virtuais" (Goffman, 1988: 41) que a exposição pública envolve caracterizam uma diferença que aparece como desvio, (re)produz estigmas e impõe ônus específicos para as mulheres.

A discussão dos dados produzidos pela pesquisa, apresentada a seguir, procura levar em conta essa complexidade. 


\section{As revistas semanais e o reforço às divisões e papéis tradicionais de gênero}

A sub-representação das mulheres é bastante acentuada nas secções de notícias das revistas semanais analisadas (Veja, Época e Carta Capital). ${ }^{2}$ Elas são apenas $10,1 \%$ das personagens citadas nas secções de notícias. O percentual de presença feminina cresce apenas entre os "populares", pessoas anônimas que são entrevistadas para dar colorido às reportagens: alcançam, então, $37,8 \%$ das personagens citadas, enquanto são $6,9 \%$ das personagens ligadas ao executivo, $8,6 \%$ das personagens ligadas ao legislativo, $12,7 \%$ daquelas ligadas ao judiciário e apenas $9,9 \%$ das personagens que são apresentadas como vozes "técnicas", ligadas a alguma competência específica e reconhecida (economistas, cientistas políticos, médicos, especialistas de áreas diversas). Entre os candidatos ao cargo de deputado federal, no segundo semestre de 2006, 5,1\% são mulheres (contra 12,6\% de candidaturas femininas registradas no Tribunal Superior Eleitoral); entre os candidatos a senador, $7 \%$ são mulheres (contra 16,5\% de candidaturas femininas registradas no Tribunal Superior Eleitoral) - nesses dois casos, além do problema mais amplo da sub-representação política das mulheres, inclusive em relação à cota de $30 \%$ prevista pela legislação brasileira, ${ }^{3}$ temos a indicação de que existe um problema específico de sub-representação das mulheres nos noticiários políticos.

A presença feminina é, ainda, concentrada num número reduzido de mulheres. Entre as personagens mais citadas nas secções de notícias políticas das revistas Veja, Época e Carta Capital, em 2006 e 2007 (aquelas presentes em 40 ou mais matérias), há apenas uma mulher, a senadora Heloisa Helena, que foi candidata à presidência da República nas eleições de 2006. Vale observar que sua presença foi concentrada no período eleitoral, praticamente desaparecendo das revistas em 2007.

Além de Helena, as mulheres presentes com maior freqüência foram a candidata, depois ministra, Marta Suplicy, e a ministra da Casa-Civil e então pré-candidata do PT à presidência da República Dilma Rousseff.

Além de reduzida e concentrada em poucas mulheres, a presença feminina nos noticiários é acompanhada por estereótipos e compreensões marcadamente redutoras sobre a participação política feminina. Em matéria da revista Veja de 26/07/2006, intitulada "Política é coisa de homem?", a

\footnotetext{
${ }^{2}$ Para dados mais completos da pesquisa "Determinantes de gênero, visibilidade midiática e carreira política no Brasil”, cf. Miguel e Biroli (2011).

${ }^{3}$ Vale lembrar que, pela lei brasileira, esse percentual é reservado entre as candidaturas apresentadas pelos partidos e não entre os assentos no parlamento. Além disso, os 30\% não podem ser ocupados pelos homens, mas não precisam ser obrigatoriamente preenchidos.
} 
TABELA 1 - Personagens do noticiário político das revistas, por número de matérias em que aparecem (2006-2007)

\begin{tabular}{l|c}
\hline \multicolumn{1}{c|}{ Nome } & Matérias \\
\hline Luiz Inácio Lula da Silva & 451 \\
\hline Geraldo Alckmin & 219 \\
\hline Fernando Henrique Cardoso & 151 \\
\hline José Serra & 137 \\
\hline José Dirceu & 111 \\
\hline Antônio Palocci & 81 \\
\hline Aécio Neves & 68 \\
\hline Fernando Collor de Melo & 60 \\
\hline Anthony Garotinho & 55 \\
\hline Tarso Genro & 51 \\
\hline Marcos Valério & 48 \\
\hline Heloísa Helena & 47 \\
\hline Márcio Thomaz Bastos & 47 \\
\hline Aloísio Mercadante & 46 \\
\hline José Sarney & 44 \\
\hline Aldo Rebelo & 43 \\
\hline Ciro Gomes & 41 \\
\hline Tasso Jereissatti & 41 \\
\hline Antônio Carlos Magalhães & 40 \\
\hline Outros & 6.866 \\
\hline Anônimos & 721 \\
\hline Total & 76 \\
\hline Fon & 48 \\
\hline
\end{tabular}

Fonte: pesquisa "Determinantes de gênero, visibilidade midiática e carreira política no Brasil"

explicação de que "de acordo com a lei eleitoral, os partidos políticos devem reservar 30\% das vagas a que têm direito nas eleições para mulheres que querem ser candidatas" é acompanhada da afirmação de que a regra "não tem respaldo na realidade" porque "o interesse feminino pela política é muito menor do que o masculino". Segundo a revista, a base para essa afirmação é o fato de $88 \%$ dos candidatos a deputados federais nas eleições de 2006 terem sido homens - nada é dito, obviamente, sobre o fato de que esse percentual se amplia quando se trata de observar a representação dos candidatos homens nas revistas: no caso, como foi dito, aproximadamente 95\% das menções a candidaturas presentes nas secções de notícias. 
Partimos, então, dessas constatações para discutir como se configura a presença das três mulheres mais citadas, Heloisa Helena, Marta Suplicy e Dilma Rousseff. Para tanto, selecionamos todas as matérias em que essas três mulheres foram citadas, nas três revistas analisadas, ao longo de todo o ano de 2006 e do primeiro semestre de 2007. Além disso, para que fosse possível comparar a presença feminina à masculina também neste caso, analisamos a presença do ministro da Justiça Márcio Thomaz Bastos no mesmo período. A escolha de Bastos se deveu ao fato de que o ministro tem uma visibilidade relativa percentualmente próxima à das mulheres mencionadas e, ainda, à hipótese confirmada em pré-teste de que poderia ser um contraponto significativo às representações das três personagens femininas analisadas.

Consideradas as 4 personagens, foram selecionadas todas as matérias em que estiveram presentes, somando 312 textos -93 relativas a Heloisa Helena, 83 a Dilma Rousseff, 72 a Márcio Thomaz Bastos e 64 a Marta Suplicy. ${ }^{4}$ Os textos estão distribuídos desigualmente entre os três períodos (semestres) analisados $-76,3 \%$ da presença de Helena acontece no período eleitoral, enquanto Rousseff e Suplicy estão presentes de maneira mais concentrada no terceiro período da pesquisa, após as eleições (48,19\% das menções a Rousseff e 46,8\% das menções a Suplicy). A presença de Márcio Thomaz Bastos é maior no período eleitoral do que nos demais (41,6\%), mas é a que aparece distribuída de maneira mais equilibrada entre os períodos. Para cada texto, foi feita uma ficha que orientou a leitura, com categorias que permitiram uma comparação entre os textos, os veículos e as personagens analisadas.

A distribuição das personagens entre as revistas não apresenta muitas diferenças. Heloisa Helena está mais presente em Veja, que concentra $38,7 \%$ de suas menções no material (contra 32,3\% em Carta Capital e $29 \%$ em Época); Marta Suplicy tem sua presença ainda mais concentrada em Veja (51,6\%, contra 29,7\% em Época e 18,8\% em Carta Capital). A presença de Dilma Rousseff acompanha a seqüência de Helena e Suplicy, com 43,4\% em Veja, 32,5\% em Época e 24,1\% em Carta Capital, enquanto a de Márcio Thomaz Bastos é a mais concentrada entre as personagens analisadas: $59,7 \%$ das menções a ele estão na revista Veja, contra 31,9\% em Carta Capital e apenas 8,3\% em Época. ${ }^{5}$

\footnotetext{
${ }^{4}$ Cada matéria em que uma das personagens é mencionada gerou uma "entrada" na base de dados (o que corresponde a uma ficha de análise em que foram listados aspectos relevantes, para a pesquisa, das representações dessas personagens). O total de 312 corresponde, assim, ao número de matérias em que houve pelo menos uma menção a uma das personagens no material analisado.

5 Vale observar que a concentração da presença de Márcio T. Bastos em Veja está relacionada ao fato de que, ao longo de 2006, ele é a principal voz em defesa do governo em matérias sobre escândalos.
} 
A presença das quatro personagens pode, também, ser observada de acordo com seu destaque nas matérias, como se vê na tabela abaixo:

TABELA 2 - Centralidade das personagens nas matérias das revistas semanais brasileiras, 2006 e 2007

\begin{tabular}{l|c|c|c|c}
\hline \multicolumn{1}{c|}{ Nome/Posição } & Central & Secundária & $\begin{array}{c}\text { Apenas } \\
\text { mencionada }\end{array}$ & TOTAL \\
\hline Dilma Rousseff & $25,3 \%(21)$ & $24,1 \%(20)$ & $50,6 \%(42)$ & $100 \%(83)$ \\
\hline Heloisa Helena & $38,7 \%(36)$ & $26,9 \%(25)$ & $34,4 \%(32)$ & $100 \%(93)$ \\
\hline Marta Suplicy & $17,2 \%(11)$ & $42,2 \%(27)$ & $40,6 \%(26)$ & $100 \%(64)$ \\
\hline Márcio T. Bastos & $20,8 \%(15)$ & $43,15(31)$ & $36,1 \%(26)$ & $100 \%(72)$ \\
\hline TOTAL & $26,6 \%(83)$ & $33 \%(103)$ & $40,4 \%(126)$ & $100 \%(312)$ \\
\hline
\end{tabular}

Fonte: Pesquisa "Gênero e política na mídia brasileira"

Vale observar que a personagem mais citada, Heloisa Helena, é também a personagem que recebe mais destaque, tendo centralidade em $38,7 \%$ das matérias em que é mencionada. Esse dado, como se pode supor, tem relação direta com sua candidatura à Presidência da República nas eleições de 2006. No primeiro semestre de 2007, ela praticamente desaparece nas secções de notícias das revistas (está presente em apenas 3 ou $0,35 \%$ das 85 menções às personagens analisadas ao longo desse período e, em todos os casos, é apenas mencionada), o que é relevante para se pensar quais são os critérios que definem a visibilidade na mídia noticiosa.

No que se refere aos estereótipos de gênero presentes nos noticiários, a pesquisa "Determinantes de gênero, visibilidade midiática e carreira política no Brasil" mostrou que existe uma correlação relevante entre o sexo das personagens e as temáticas às quais estão vinculadas. Os homens, além de mais presentes quantitativamente em todo o material analisado, concentram sua presença em temas que têm maior destaque, ocupando posições mais centrais nas secções de notícias das revistas. Em 28,1\% dos casos, sua presença é nas secções políticas, contra $14 \%$ da presença das mulheres; $3,9 \%$ dos homens estão presentes nas secções de notícias econômicas, contra $1,5 \%$ das mulheres. Por outro lado, as mulheres têm maior concentração nas secções de faits-divers ( $49,8 \%$ contra $31,8 \%$ dos homens), cidades $(4,3 \%$ contra $1,5 \%$ dos homens) e educação $(1,1 \%$ contra $0,4 \%)$. Vale ressaltar que as duas primeiras, faits-divers e cidades, são as categorias temáticas em que se encontra o maior número de "populares", personagens às quais não é associada nenhuma competência específica. 
Observados esses dados, passamos aqui a uma outra dimensão desses estereótipos, também relacionada diretamente à representação de mulheres e homens nos noticiários. As análises realizadas permitiram observar a presença de enunciados que caracterizam as personagens, distribuídos em três eixos: (1) personalidade e feminilidade; (2) corporalidade; (3) vida privada.

Vale ressaltar que, neste ponto, os aspectos quantitativos perdem relevância. Entende-se que a presença de enunciados que explicitam ou indicam uma problemática de gênero, mesmo que seja estatisticamente pouco relevante, permite discutir aspectos significativos das divisões e hierarquias de gênero na mídia noticiosa e na política. Essa posição se acentua quando essas marcas (estereótipos de gênero) são analisadas tendo-se em mente os dados relativos à sub-representação das mulheres nos noticiários.

As noções de formação discursiva, enunciado e arquivo, tais como trabalhadas por Michel Foucault (1997), assim como a noção de comentário, trabalhada pelo mesmo autor (1996), orientam a visão que temos de que o noticiário jornalístico participa de uma dinâmica discursiva caracterizada pela retomada de discursos historicamente cristalizados, nos quais a oposição entre masculinidade e feminilidade se mantém e está associada a papéis convencionais de gênero. Esses discursos, ainda que retomados pontualmente, estabelecem os limites para a produção de novos discursos. Isso significa que o que é dito nas revistas não é o mesmo que foi dito décadas antes - e falar em estereótipos não significa falar em permanências intocadas. Mas é, por outro lado, delimitado por pressupostos e condições que atualizam representações de gênero nas quais a mulher existe em posição de exterioridade ou de marginalidade em relação ao campo político. A negação, freqüente, de que existe um problema de gênero, a presença reduzida das mulheres nos noticiários e os estereótipos que serão discutidos a seguir compõem essas retomadas - pontuais, porém produtivas justamente porque ativam representações de gênero que têm efeitos sobre a compreensão da sub-representação feminina na política e sobre as carreiras das mulheres que procuram inserir-se ou manter-se nesse campo.

\subsection{Personalidade e feminilidade}

Em busca de pistas relativas às marcas de gênero existentes no material, foram selecionadas, entre as 312 matérias que compõem o corpus da pesquisa, todas aquelas em que há alguma menção à personalidade das personagens analisadas. Personalidade é entendida, aqui, em sentido bastante amplo: foram selecionadas quaisquer referências a um modo de ser próprio a um determinado indivíduo, que o caracterizaria, incluindo o que se costuma chamar de temperamento, assim como comportamentos, hábitos e gostos. 
Em 7\% dos casos, ou 22 matérias entre as 312, há alguma referência à personalidade assim compreendida. Nesse quesito, Heloisa Helena está à frente das demais, com 14 dessas referências, contra 3 nos casos de Dilma Rousseff e Marta Suplicy e 2 no de Márcio Thomaz Bastos. Feita a seleção desses textos, analisamos os enunciados que constituem essas referências.

Vale destacar, inicialmente, que a única referência ao feminismo em todo o material selecionado aparece nesse segmento do material. Dilma Rousseff, segundo reportagem da revista Carta Capital publicada em 19/04/2006, seria uma "figura complexa": "é durona, mas é feminina. Sem ser feminista". A essa afirmação se segue a de que "tem um temperamento forte e é tida como uma negociadora intransigente e técnica", associando à ministra o rótulo de "Dama de Ferro". A reportagem refere-se ao encontro entre Rousseff e a presidente do Chile, Michelle Bachelet, e é intitulada "Jogo de Damas".

As referências à personalidade de Heloisa Helena foram feitas em matérias publicadas no segundo semestre de 2006. Há, em todos os casos, um entrecruzamento com representações da feminilidade. Um exemplo é a reportagem da revista Veja dedicada a Heloisa Helena, publicada em 26/07/2006: a então candidata à presidência seria "uma das poucas [mulheres] que gostam de política”. No material, seu caráter é associado ao afeto, à impulsividade e à honestidade, com críticas ao que seria um radicalismo sem lugar no presente. De um lado, o radicalismo está associado a uma postura "Cabra-Macho"; ${ }^{6}$ de outro, sensibilidade, honestidade e suavidade aparecem ligadas a alguma essência feminina ou a representações convencionais da feminilidade. Citamos alguns exemplos: (1) as afirmações de que ela tem caráter, honestidade, integridade e é a antítese do político profissional vêm acompanhadas das afirmações de que "fala sempre como mãe" e tem "aversão à vaidade feminina"; em outro caso, (2) "representa a esperança, lealdade, honestidade, hombridade e respeito pelo próximo; mostra o que há de melhor na essência feminina"; (3) "de perigosa subversiva a suave mulher, a senadora tenta, na campanha, se desvincular da imagem de radical e intransigente"; e, ainda, (4) caracterizada como "mistura de udenista e beata”, "esperneante Rosa Luxemburgo", é associada aos adjetivos "fera" e "fofa".

As referências a Marta Suplicy, por sua vez, são interessantes por apresentarem um indício de diferenças no tratamento da problemática de gênero

\footnotetext{
${ }^{6}$ Segundo reportagem publicada pela revista Carta Capital em 09/08/2006, sobre as estratégias dos candidatos à Presidência, Heloisa Helena estaria dividida entre "manter a postura Cabra-Macho que provocou a ascensão nas pesquisas, mas com efeitos colaterais no quesito rejeição, ou suavizar o discurso".
} 
entre as revistas, associado a posições políticas diferentes no contexto em que foram produzidas as reportagens. Das três menções à personalidade de Suplicy, 2 estão em Carta Capital e 1 em Veja. Em Carta Capital, uma delas está presente na já mencionada reportagem "Jogo de Damas", que traz a seguinte legenda a uma foto de Suplicy: "Impor-se com feminilidade é meta de Marta Suplicy". Nessa matéria, a voz da atual ministra do Turismo está presente, enunciando que "Há certos momentos em que tenho que ser dura, falar grosso", ao mesmo tempo em que teria dito: "Sou feminina". O segundo caso, na mesma revista, em que a personalidade de Suplicy é citada consiste em uma reportagem que relaciona de forma crítica personalidade na esfera pública e feminilidade, no contexto da reforma ministerial, mencionando o fato de que homens e mulheres recebem julgamentos diferentes na esfera pública: "mulher com atitude é histérica e desaforada" (Carta Capital, 21/02/2007).

Já a reportagem da revista Veja (14/03/2007) apresenta uma Marta Suplicy pouco valorizada por seu partido (o PT), que teria como característica o fato de estar sempre tramando para conquistar posições de poder. Vale destacar que a visibilidade de Marta Suplicy em Veja se divide entre dois eixos predominantes: (1) a busca por um ministério no início de 2007, em que é retratada como fraca e desprestigiada por Lula, e (2) a associação entre seu nome e denúncias de corrupção envolvendo integrantes de sua equipe na Prefeitura de São Paulo. A essa visibilidade, associam-se clichês de gênero como a caracterização da já ministra Marta Suplicy como "sexóloga e ministra do Turismo 'sexual", na coluna Veja essa da edição de 20/06/2007, e uma associação entre Suplicy e Rosinha Matheus, afirmando que ambas teriam entrado na política "graças ao prestígio político dos seus maridos”. Essa matéria foi publicada em 15/02/2006 e será discutida mais adiante, na seção Vida privada.

Thomaz Bastos, personagem menos caracterizada no que se refere à personalidade, permite um contraponto interessante com as personagens femininas analisadas. É caracterizado de duas formas: (1) econômico, em caracterização irônica (ao mobiliar seu apartamento, orienta os decoradores a negociar os preços dos móveis, mas chega a pagar 11 mil reais em um tapete, segundo reportagem publicada em Veja em 14/02/2007); (2) "pode ser muitas coisas, menos ingênuo", afirmação que, no contexto das denúncias de corrupção, pode ganhar conotação negativa (não está dizendo a verdade, sabe e mente), mas que o coloca em uma posição bastante diferente daquelas em que são colocadas as três mulheres - aqui, pode-se dizer, predominam racionalidade e astúcia (mesmo que não honestidade). 
Fica indicada, mais uma vez, a hipótese, dentro dos limites do material analisado, de que as menções ao ministro Márcio Thomaz Bastos estão associadas a representações da masculinidade que funcionam como contraponto significativo às representações da feminilidade presentes no material. Voltaremos a essa hipótese nos próximos itens.

\subsection{Corporalidade}

Entre as revistas analisadas, dentro do período pesquisado, foi selecionado todo material que traz referências aos corpos das personagens, com destaque para a aparência física. Entende-se que a mera referência ao corpo indica um modo de enquadrar a existência pública dessas personagens. A análise dos enunciados que constituem essas referências permite, então, uma compreensão maior das conexões entre corporalidade e outros elementos que organizam as divisões de gênero nas secções de notícias das revistas.

Em apenas 3,2\% ou 10 das matérias, há menções à aparência física das personagens analisadas. Vale ressaltar que, no período analisado, não há qualquer menção à aparência física do ministro Márcio Thomaz Bastos.

Há apenas uma menção indireta à aparência da ministra Dilma Rousseff. Trata-se de uma referência ao fato de que a ministra estaria fazendo uma dieta para perda de peso (Veja, 22/02/2006). Vale observar que um desdobramento da pesquisa, ainda em andamento, permite observar que, quando a ministra ganha mais visibilidade em 2008, suas representações são mais marcadas pela problemática de gênero e a relação entre competência pública e feminilidade se estabelece de forma mais clara. Além de caracterizações como "mãe do PAC" e "Geisel de saias", reproduzidas pelas revistas, a possibilidade de que seja candidata à Presidência abre toda uma agenda da corporalidade nas reportagens: multiplicam-se os comentários relacionados à aparência, especialmente referentes a dietas alimentares para emagrecer, tendo como exemplo mais acabado da visibilidade dada ao corpo feminino entrevistas com um cirurgião plástico (que recomenda um tratamento com laser para rejuvenescer) e com uma consultora de moda (que recomenda mudanças nas roupas, cabelo e óculos da ministra). ${ }^{7}$

No caso de Marta Suplicy, duas reportagens trazem referências à aparência física. Em uma delas, menciona-se o fato de que se apresenta em público "invariavelmente de tailleur ou vestido". Em outra reportagem (Época, 21/08/2006), dedicada a projeções sobre o comportamento eleitoral das

\footnotetext{
7 Época, 21/04/2008. A matéria apresenta, ainda, o "conselho" do publicitário Lula Vieira: Dilma deveria transformar o "jeito durão" em "estilo mãe". Em janeiro de 2009, a ministra submeteu-se a cirurgias plásticas com o objetivo de obter uma aparência considerada mais adequada às disputas eleitorais de 2010.
} 
mulheres nas eleições de 2006, atribui-se à cientista política Lúcia Hipólito a opinião de que não existe "voto de gênero". Nas palavras atribuídas a Hipólito, "Marta Suplicy, na Prefeitura de São Paulo, teve enorme rejeição entre as mulheres com seu estilo Chanel na lama".

As referências a Heloisa Helena estão presentes em maior quantidade, indicando uma relação proporcional entre visibilidade e marcas de gênero, como no caso já mencionado de Dilma Rousseff. São várias as referências: (1) retomadas de caracterizações e julgamentos sobre um visual considerado simples demais para uma candidata à Presidência, associando "pureza socialista", "vitória da calça jeans e rabo-de-cavalo" e propostas de governo que resultariam em uma catástrofe para o país, caso fossem implementadas (Veja, 26/07/2006); ou ainda, em Carta Capital (13/11/2006), "a HH, da blusinha branca, do blue jeans e do vernáculo em chamas” é vinculada a caracterizações da feminilidade, "com seu figurino propositalmente casto, a Che Guevara de saias"; (2) uma observação fina da aparência - os longos cabelos presos em rabo-de-cavalo como marca registrada ou, mais raramente, "cabelo solto, encaracolado à custa de baby liss e levemente esvoaçante”, sobrancelhas recém-acertadas, cílios pintados (longos), maquiagem 'bem natural'", como descreve uma nota na coluna Gente da revista Veja (01/03/2006) sobre $o$ tratamento dado à aparência de Heloisa Helena em fotos para a seção Visual Novo da revista Cláudia; (3) observações que tornam visível o corpo, sexualizando a presença da mulher na esfera pública - "seu corpo é de carne pouca", tem "pernas bem feitas" -, ao mesmo tempo em que a vinculam à maternidade e a família, ao caracterizá-la como "mãe leoa", que "fala sempre como mãe" (Época, 14/08/2006). ${ }^{8}$ Há, ainda, afirmações como a de que precisa ganhar peso (Veja, 10/05/2006) e a de que a "cara de professora" seria sua marca registrada, dita, supostamente, pela própria candidata (Veja, 01/03/2006).

Vale ressaltar que está presente, aqui, uma das tensões ligadas à representação de mulheres na esfera pública, especialmente na esfera de visibilidade midiática: as referências à aparência física e a aspectos entendidos como vinculados à feminilidade podem constituir um obstáculo, ao reforçarem

\footnotetext{
${ }_{8}^{8}$ Vale registrar o seguinte trecho da reportagem publicada em Época, que traz perfil de Heloisa Helena escrito por Ruth de Aquino: "Estilo agri-doce, morde-e-assopra. Fala, sempre, como mãe. Mãe leoa, marxista e cristã, enfermeira e professora. Seu modelito - camisa branca de algodão com babadinhos, jeans desbotado e sandália plataforma com meia - não corre o menor perigo de virar moda. Só combina com o jeito $\mathrm{HH}$ de ser. Serve para marcar a aversão à vaidade feminina e facilitar o trabalho dos chargistas". Na mesma reportagem, "dois desafios parecem intransponíveis: convencer Heloisa a não esconder as pernas bem-feitas e a soltar os cabelos. 'Minha filha', disse ela, 'se eu soltar os cabelos pra foto vão dizer que não sou a mesma; depois de ter filho, para amamentar e andar de ônibus, só dá pra andar de rabo-de-cavalo”.
} 
uma visão estigmatizada (a comparação com Márcio Thomaz Bastos pode indicar que essa é uma questão relevante, uma vez que não há qualquer menção à aparência física no caso do ministro), mas também podem ser um recurso para a construção de uma identidade diferenciada da dos homens, ou uma estratégia para conquistar visibilidade.

Essa tensão remete a um problema mais amplo, mencionado antes neste artigo. Por um lado, o apagamento das marcas de gênero pode reforçar uma concepção universal de indivíduo que nega que as diferenciações existem socialmente e que as relações de poder são perpassadas pelo gênero. Por outro lado, porém, a presença enquanto mulheres, vinculada a estereótipos que remetem à maternidade e à sexualidade, para citar apenas dois exemplos, remete a representações convencionais e restritivas, naturalizadas nas reportagens. A exigência difusa de que as mulheres se comportem enquanto bomens quando se encontram em posições de maior destaque, ou para que a elas tenham acesso, convive com a exigência de que as mulheres se comportem enquanto mulheres. Nos dois casos, mantêm-se critérios androcêntricos para o julgamento do comportamento feminino, que atam as mulheres a comportamentos convencionais ou as restringem aos comportamentos considerados legítimos em esferas predominantemente masculinas.

\subsection{Vida privada}

As referências à vida privada das personagens englobaram, na seleção feita, menções a familiares, de um lado, e menções a aspectos da vida entendidos comumente como do âmbito pessoal, íntimo, doméstico, afetivo, não-público.

Ao todo, as referências à vida privada estão em 5,76\% do material, ou 18 matérias entre as 312 analisadas. Há apenas 9 menções a familiares.

Vale ressaltar, primeiramente, que não há nenhuma referência a familiares no caso de Márcio Thomaz Bastos, repetindo o que ocorre no eixo anterior, em que apenas no caso do ministro não havia qualquer referência à aparência física. As referências a sua vida anterior e/ou distinta de suas funções como ministro são todas a sua posição profissional (profissional bem-sucedido, advogado criminalista de sucesso, com "carreira invejável no campo estritamente criminal, que se expressou tanto em prestígio quanto em patrimônio") e à amizade com poderosos, como o ex-senador, ex-governador da Bahia e ex-ministro Antonio Carlos Magalhães. Bastos é caracterizado como alguém que, antes dos escândalos do governo Lula, seria dono da "tranqüilidade e simpatia espontâneas dos profissionais bem-sucedidos e dos homens felizes na sua vida pessoal" (Veja, 31/05/2006). Na mesma reportagem, há uma referência à alimentação e aos gostos pessoais, 
ao ser caracterizado como "apreciador de boa literatura, pintura moderna e bons vinhos". Esse quadro de referências difere de maneira relevante das referências a casamento, maternidade, roupas e dietas no caso das mulheres analisadas. Parece haver uma relação entre representações da competência masculina na esfera pública e representações da masculinidade que exclui, de maneira significativa, a vida familiar e afetiva.

No caso da ministra Dilma Rousseff, as referências são a sua formação como economista e a sua competência técnica, aos amigos dos tempos de combate à ditadura militar instaurada no Brasil em 1964, mas também a sua idade, a sua filha, ao fato de ser divorciada e a uma dieta alimentar, como se indicou antes. Junto com a publicação de uma entrevista com a ministra, a revista Época (30/01/2006) menciona a cidade natal da ministra e o fato de ser divorciada e ter uma filha. Como "curiosidade", menciona o fato de gostar de "pintura e cultura chinesa".

No caso de Marta Suplicy, há referências pontuais ao atual marido (em uma matéria de Veja de 03/05/2006, em que aparece em fotografia ao lado de Luis Favre) e uma ao ex-marido, em reportagem de Veja $(15 / 02 / 2006)$ que associa Suplicy à governadora do Rio de Janeiro Rosinha Garotinho e à estrela da reportagem, a primeira-dama de Salvador, Maria Luíza - mulheres que, diferentemente de Suplicy, não tiveram em qualquer momento trajetória pública dissociada da de seus maridos. Depois de caracterizar Maria Luíza de maneira bastante irônica, ridicularizando sua influência sobre o marido, apresenta o seguinte enunciado: "Assim como Rosinha Matheus e Marta Suplicy, que também entraram na política graças ao prestígio político dos seus maridos, Maria Luíza prepara-se para alçar vôos mais altos".

Mais uma vez, é no caso de Heloisa Helena que as referências se multiplicam. Por ter disputado as eleições de 2006, há referências a seu patrimônio, a sua origem e carreira como professora universitária na Universidade Federal de Alagoas, mas também a suas relações com a mãe e com os irmãos, aos filhos e à maternidade. Há, ainda, uma menção a um suposto relacionamento com o senador Luiz Estevão. Este é, ainda, um caso em que se pode observar uma forte acomodação entre os enquadramentos de gênero presentes na mídia e as estratégias da candidata. Segundo o material analisado, é a própria Heloisa Helena que se refere inúmeras vezes à maternidade - teria prometido, por exemplo, "acolher todas as crianças e jovens da maneira como acalenta seus filhos” (Época, 14/08/2006). Esse aspecto de sua auto-apresentação, ressaltado no material jornalístico, colabora para uma vinculação entre a atuação pública de mulheres e uma identidade feminina cristalizada e redutora. 
Ressalta-se, novamente, que as menções ao ministro Márcio Thomaz Bastos estão associadas a representações da masculinidade que funcionam como contraponto significativo às representações da feminilidade presentes no material. Há um conjunto distinto de referências (ou de silêncios) que permitem falar na presença de estereótipos de gênero.

\section{Considerações finais}

Neste ponto, retomamos questões que perpassam o artigo: existem marcas de gênero na maneira como as personagens analisadas estão representadas nas secções de notícias? Se sim, pode-se falar em estereótipos de gênero? As análises indicam que a resposta é positiva nos dois casos.

A presença feminina nos noticiários políticos oscila entre a invisibilidade e uma alteridade marcada por estereótipos. A visibilidade ligada ao corpo aparece como marca negativa porque identifica as mulheres como dissonantes em relação ao ideal de um debate livre de especificidades, particularidades e afetos, sem que promova a politização das questões relacionadas ao corpo e à esfera privada. A seletividade temática caminha, assim, junto com uma visibilidade também seletiva, em que as fronteiras entre idéias e corpo, entre razão e afeto e, de maneira mais ampla, entre público e privado confirmam "pertencimentos" sociais diversos. O fato de que o corpo e aspectos da vida privada (e familiar) das mulheres serem tematizados - enquanto outros aspectos da trajetória dos homens ganham relevância - está diretamente ligado às pressões, exigências e critérios de julgamento diferenciados impostos a homens e mulheres.

Ao mesmo tempo, porém, que a visibilidade diferenciada pode ser considerada um ônus para as mulheres (porque confirma os papéis sociais convencionais e as relaciona a competências e atividades socialmente desvalorizadas, quando se trata da atuação na esfera pública), ela pode ser também um recurso para a construção de sua persona política, uma vez que essas distinções têm impacto sobre a definição do que é "fato" no cotidiano jornalístico e fazem parte das conexões entre agenda e voz. Em outras palavras, deve-se tomar em conta que a opção pela invisibilidade muitas vezes é considerada, por parte das próprias mulheres, pior do que o recurso aos estereótipos tradicionais para inserir-se na agenda ou ampliar a presença em coberturas específicas.

Ressaltamos a relevância do controle feito por meio da análise das representações do então ministro Márcio Thomaz Bastos. Essa comparação permitiu observar que algumas das marcas, quantitativamente restritas, são parte de séries discursivas que demarcam um conjunto de referências para o julgamento da atuação feminina em qualquer esfera, estabelecendo uma continuidade entre um papel que seria reservado às mulheres na vida privada 
(o de mãe, mulher afetiva e zelosa com a própria aparência) e o papel que teriam na vida pública. A especificidade de sua atuação na política estaria justamente em colocar em relevo esse "fundo comum" - um denominador comum feminino acompanhado de julgamentos que estabelecem as divisões entre comportamento adequado e inadequado.

Há, assim, uma oscilação entre a expectativa de que a mulher se apresente, na política, enquanto mulher, e um conjunto de julgamentos referenciados pela presença masculina na política e por representações da masculinidade, conectando a competência na esfera pública a atitudes entendidas como masculinas ou masculinizadas.

Como se mencionou antes a partir da discussão feita por Carole Pateman (1990), as mulheres vêm sendo excluídas e incluídas na esfera pública enquanto mulheres, isto é, pelas significações e formas de valorização associadas ao que se entende como feminilidade - noção definida, predominantemente, em relação às representações hegemônicas da masculinidade. Da perspectiva que assumimos, como se disse antes, é preciso levar em consideração que o recurso aos papéis sociais tradicionalmente reservados às mulheres pode ser, ao mesmo tempo, um obstáculo a uma atuação política mais destacada $e$ uma estratégia de diferenciação e ação política por parte das mulheres.

Estratégias diferenciadas podem levar a identidades de gênero também distintas. As diferenças entre as representações das três mulheres analisadas são resultado de suas trajetórias pessoais, de suas carreiras e diferentes formas de inserção na vida pública, de formas diferenciadas de "gestão" de sua visibilidade. Nas revistas analisadas, porém, essas identidades distintas são conectadas em discursos comuns sobre a feminilidade e sobre as relações entre mulheres e política. Encontram-se, assim, em um campo comum - o das representações estereotipadas da feminilidade -, o que é explicitado, na análise, pelo contraponto com as representações do então ministro Márcio Thomaz Bastos.

A presença restrita, do ponto de vista quantitativo, de estereótipos de gênero deve ser compreendida no contexto mais amplo da invisibilidade feminina nos noticiários. Como mostram as pesquisas realizadas, a forma atual da divisão entre os sexos nas secções de notícias políticas das principais revistas semanais brasileiras reserva às mulheres a invisibilidade, combinada a uma presença marginal, isto é, vinculada a áreas de menor prestígio político e a temáticas de menor prestígio no noticiário. Sua presença é, assim, reduzida, concentrada em poucas mulheres e acompanhada por marcas quantitativamente restritas, porém significativas, que remetem a estereótipos de gênero que atualizam divisões convencionais entre masculinidade e feminilidade. 


\section{Referências bibliográficas}

Badinter, Elizabeth (1980), O amor incerto: história do pensamento maternal do século XVII ao século XX. Lisboa: Relógio D'Água.

Badinter, Elizabeth (2005), Rumo equivocado: o feminismo e alguns destinos. Rio de Janeiro: Civilização Brasileira.

Biroli, Flávia (2010), "Gênero e família em uma sociedade justa: adesão e crítica à imparcialidade no debate contemporâneo sobre justiça", Revista de Sociologia e Política, 18(36), 51-65.

Carroll, Susan J.; Schreiber, Ronnee (1997), "Media Coverage of Women in the 103rd Congress", in Pippa Norris (org.), Women, Media and Politics. New York, Oxford: Oxford University Press, 131-148.

Foucault, Michel (1996), A ordem do discurso. São Paulo: Ed. Loyola.

Foucault, Michel (1997), A arqueologia do saber. $5^{\mathrm{a}}$ ed. Rio de Janeiro: Forense Universitária.

Fraser, Nancy (1997), Justice Interruptus: Critical Reflections on the "Postsocialist" Condition. New York: Routledge.

Goffman, Erving (1986), Frame Analysis: An Essay on the Organization of Experience. Boston: Northeastern University Press.

Goffman, Erving (1988), Estigma: notas sobre a manipulação da identidade deteriorada. Rio de Janeiro: LTC.

Gomes, Wilson (2008), "Mapeando a audioesfera política brasileira: os soundbites políticos no Jornal Nacional". Comunicação apresentada ao Grupo de Trabalho "Comunicação e Política" do XVII Encontro da Compós. São Paulo, SP: PUC-SP.

Iyengar, Shanto; Valentino, Nicholas A.; Ansolabehere, Stephen; Simon, Adam F. (1997), "Running as a Woman: Gender Stereotyping in Political Campaigns", in Pippa Norris (org.), Women, Media and Politics. New York, Oxford: Oxford University Press, 77-98.

Mccombs, Maxwell E.; Shaw, Donald L. (2000), "A função de agendamento dos media", in Nelson Traquina (org.), O poder do jornalismo: análise e textos da teoria do agendamento. Coimbra: Ed. Minerva.

Mackinnon, Catherine A. (1989), Toward a Feminist Theory of the State. Cambridge, Mass.: Harvard University Press.

Miguel, Luis Felipe; Biroli, Flávia (2008), "Gênero e política no jornalismo brasileiro", Revista Famecos, 36, Porto Alegre, 24-39.

Miguel, Luis Felipe; Biroli, Flávia (2009), "Mídia e representação política feminina: hipóteses de pesquisa”, Revista Opinião Pública, 15(1), 55-81.

Miguel, Luis Felipe; Biroli, Flávia (2010), "A produção da imparcialidade: a construção do discurso universal a partir da perspectiva jornalística”, Revista Brasileira de Ciências Sociais, 25(73), 59-76.

Miguel, Luis Felipe; Biroli, Flávia (2011), Caleidoscópio convexo: mulheres, política e mídia. São Paulo: Editora da Unesp. 
Mouffe, Chantal (2005), "Feminism, Citizenship and Radical Democratic Politics", in Chantal Mouffe, The Return of the Political. London, New York: Verso, 74-89.

Norris, Pippa (1997), "Introduction: Women, Media and Politics", in Pippa Norris (org.), Women, Media and Politics. New York, Oxford: Oxford University Press, 1-18.

Okin, Susan (1998), "Gender, the public and the private", in Anne Phillips (org.), Feminism and Politics. Oxford: Oxford University Press, 116-41.

Okin, Susan (1989), Justice, Gender, and the Family. New York: Basic Books.

Pateman, Carole (1993), O contrato sexual. Rio de Janeiro: Paz e Terra.

Pateman, Carole (1990); “Does Sex Matter to Democracy?”, Scandinavian Political Studies, 13(1), 57-63.

Schudson, Michael (1995), The Power of News. Cambridge, Massachusetts: Harvard University Press.

Thompson, John B. (1995), Ideologia e cultura moderna: teoria social crítica na era dos meios de comunicação de massa. Petrópolis: Vozes.

Tuchman, Gaye (1992), “Objectivity as Strategic Ritual: An Examination of Newsmen's Notion of Objectivity”, American Journal of Sociology, 77(4), 660-79.

Young, Iris Marion (1990), Justice and the Politics of Difference. Princeton: Princeton University Press.

Young, Iris Marion (2000), Inclusion and Democracy. Oxford: Oxford University Press. 